\title{
TRACHEOSTOMY AT A TERTIARY LEVEL HOSPITAL IN BANGLADESH: ANY CHANGE IN PATTERN?
}

\author{
TALUKDAR DC ${ }^{1}$, MAHAMUD $\mathrm{M}^{2}$, MAHMUD $^{3}$, ISLAM MS ${ }^{4}$, AKAIDUZZAMAN DGM ${ }^{5}$, LITU MA ${ }^{6}$, \\ BISWAS D $^{7}$
}

\author{
Abstract: \\ Objective: This study was conducted on tracheostomy to find out the different indications \\ and complications occured at the tertiary level hospital in Bangladesh. \\ Study design: Cross-sectional observational study.
}

Place and Duration: This study was conducted at the department of Otolaryngology \& Head Neck surgery and department of ICU, Sir Salimullah Medical College Mitford Hospital, Dhaka \& DMCH over one year from January 2014 to December 2014.

Methodology: 55 tracheostomy operation were performed in both genders and all age groups either in emergency situations or within an elective environment. All the patients were registered with a definite protocol by filling a pre designed proforma equipped with demographic data, details of present illness mirroring the indication for the procedure, relevant physical examination $\&$ investigations, details of the surgical procedure of tracheostomy and postoperative follow up with note of any attendant complications described as immediate, early and late postoperative.

Results: Mean age of this study was 40.09 years and male female ratio iwas 3.2: 1. 30(54.54\%) patients underwent emergency tracheostomy and 25(45.46\%) underwent tracheostomy electively. The commonest indications were laryngeal \& hypopharyngeal malignancies which affected $28(50.9 \%)$ patients. The overall rate of complications was $25.45 \%$. These were 4(28.57\%) immediate post operative, $8(57.14 \%)$ early post operative and 2(3.63\%) late post operative. Out of overall 14 complications, 11(36.66\%) complications occurred in 40 patients who underwent tracheostomy in emergency and 3(12\%) complications occurred in 25 patients who underwent tracheostomy electively.

Conclusion: Upper airway obstruction due to laryngeal and hypopharyngal carcinoma still remains the most common indication for tracheostomy in our centre but prolonged intubation as an indication for tracheostomy is evolving based on recent improvement in the facilities available at our ICU.

Keywords: Tracheostomy, indications, outcome, pattern.

J Dhaka Med Coll. 2016; 25(2) : 67-71

\section{Introduction:}

Tracheostomy is an age-old operation, during which the trachea is surgically opened in the anterior wall and a stoma is created to facilitate ventilation. It is one of the oldest surgical procedures described.1,2 The word tracheostomy comes from the Greek, meaning "I cut the trachea". The term tracheotomy commonly refers to the surgical incision into the trachea and tracheostomy to the creation of the stoma. ${ }^{3}$ The procedure was described in the Rig Veda, a sacred book of Hindu medicine, in $2000 \mathrm{BC}$, and was also depicted on two slabs dating back to ancient Egypt (2920-2770 BC). ${ }^{1,2,4,5}$ In eighteenth century, George Martin developed the double cannula tracheostomy tube, an idea still popular \& accepted due to the outer tube remaining in place and the

1. Dr. Debesh Chandra Talukdar, Associate Professor and RS, Department of ENT \& Head-Neck Surgery, DMCH, Dhaka.

2. Dr. Mashuque Mahamud, EMO, NIENT, Tejgaon, Dhaka

3. Dr. Sharfuddin Mahmud, Registrar (ENT), SSMC \& Mitford Hospital, Dhaka

4. Dr. Md. Shaikhul Islam, Resident Surgeon (ENT), DMCH

5. Dr. DGM Akaiduzzaman, Associate professor, Dept of ENT, SSMC \& Mitford Hospital, Dhaka.

6. Prof. Manilal Aich Litu, Head of the department, Dept of ENT, SSMC \& Mitford Hospital, Dhaka.

7. Dr. Dipali Biswas, Department of Oral Anatomy \& Physiology, City Dental College, Dhaka.

Correspondence: Dr. Sharfuddin Mahmud, Registrar, Department of ENT\&HNS, SSMCMH. Mob: 01817544133, E-mail:mahmudssmc@yahoo.com

Received: 21 March 2016

Accepted: 20 March 2016 
inner tube being removed periodically to clean $\&$ maintain the patency of the Tracheotomy tube. ${ }^{6}$ Later in 1869, Trendelenberg first introduced the use of a cuffed tracheostomy tube which later proved very beneficial in the management of the aspiration problem. ${ }^{7}$ Then throughout the nineteenth century tracheostomy enjoyed increasing popularity but the morbidity \& mortality of the procedure remained high. It was early 1900s when Chavelier Jackson standardized the procedure $\&$ demonstrated the means to reduce the morbidity $\&$ mortality by careful intra $\&$ post operative care. ${ }^{8}$

For the last 2000 years, the main indication for tracheostomy used to be the relief of the upper airway obstruction by bypassing the proximal obstruction. But with the advances in traumatology and I.C.U. care for the last 50 years, more of the patients requiring prolonged airway management through mechanical ventilatory support, need tracheostomy to have a more safe and comfortable period of weaning from mechanical ventilation which avoids complications of trans laryngeal intubation with added advantages of facilitated nursing care. Hence for the last half a century, gradually the indication of tracheostomy has been widened to include tracheobronchial toileting, protection against inhalation of foreign body and reduction of dead space and intermittent positive pressure ventilation for treatment of chronic hypoventilation due to neuromuscular disease, trauma including spinal cord injury, surgery in the face/neck region or post-stroke complications. ${ }^{10,11}$ Main indication of tracheostomy in our country particularly in adult is upper airway obstruction due to head and neck malignancy. ${ }^{12}$ Tracheostomy is a very common operation in any otolaryngology and head neck surgery department. But even in this era of antibiotics and aseptic surgery, tracheostomy is not free from complications. Although these complications are usually not serious, but occasional serious complications may arise which may cause death of the patient. ${ }^{13}$ The complications of tracheostomy can be divided into immediate postoperative (within the first 24 hours after surgery), early postoperative (within the first week after surgery) and late postoperative (beyond one week).

Tracheostomy remains a very important life saving surgical procedure worldwide and particularly in our environment where patient present late in upper airway obstruction. Little work has been done on this subject in our environment and therefore it was necessary to conduct this study to describe our own experiences with tracheostomy, common indications and outcome of tracheostomized patient in our setting and compare our results with those from other centers in home \& abroad.

\section{Methodology}

This is a cross sectional observational study which was done over one year from January 2014 to December 2014. Study was conducted at the department of Otolaryngology \& Head Neck surgery and department of ICU, Sir Salimullah Medical College Mitford Hospital \& $\mathrm{DMCH}$, Dhaka. 55 tracheostomy operation was performed in both genders and all age groups who underwent tracheostomy either in emergency situations or within an elective environment. The exclusion criteria of our study was cases with multiple systemic comorbidities including hypertension, blood disorders, chemotherapy recipients and patients on anti coagulant therapy etc. All the patients were registered with a definite protocol by filling a pre designed proforma equipped with demographic data, details of present illness mirroring the indication for the procedure, relevant physical examination \& investigations, details of the surgical procedure of tracheostomy and postoperative follow up with note of any attendant complications described as immediate, early and late postoperative.

\section{Results}

This study was done from January 2014 to December 2014. 55 consecutive patients in whom Tracheostomy was performed for different indications were included in this study. Out of 55 patients included in this study, $42(76.36 \%)$ were male and $13(23.64 \%)$ were female showing male preponderance. The age ranged from 4 years to 70 years. The most 
frequent age group which underwent tracheostomy was $40-50$ years $\&$ it accounted $17(30.9 \%)$ patients. 30(54.54\%) patients underwent emergency tracheostomy and 25(45.46\%) underwent tracheostomy electively. In $40(72.72 \%)$ patients, tracheostomy was done in operation theatre and in $15(27.28 \%)$ patients tracheostomy was done at bedside in intensive care unit. The indications for tracheostomy were varied. Most of the patients were suffering from laryngeal and hypopharyngeal malignancies and they accounted $28(50.9 \%)$ patients. Among other indications, 9(16.36\%) patients need tracheostomy for prolonged ventilation due to Guillain Barre Syndrome and $6(10.9 \%)$ patients for prolonged ventilation due to cerebrovascular accidents. Less common indications included 2(3.63\%) patients each for maxillary carcinoma, anaplastic carcinoma of thyroid, Ludwig's angina and badly impacted foreign bodies at laryngopharyngeal level causing severe stridors. In this study $1(1.81 \%)$ patient was tracheostomized each for nasopharyngeal carcinoma, multiple papilloma of larynx, cut throat injury and bilateral vocal cord paralysis.

Complications occurred in 14 patients, showing a complication rate of $25.45 \%$. These were $4(28.57 \%)$ immediate post operative, $8(57.14 \%)$ early post operative and $2(3.63 \%)$ late post operative. Out of overall 14 complications, $11(36.66 \%)$ complications occurred in 40 patients who underwent tracheostomy in emergency. Similarly, 3(12\%) complications occurred in 25 patients who underwent tracheostomy electively. Still categorizing, among the electively done $1(33.33 \%)$ complication occurred immediate post operative, $2(66.66 \%)$ occurred in early postoperative period \& no late post operative complication. Similarly among the tracheostomies done in emergency, 4(36.36\%) complication occurred immediate post operative, $6(54.54 \%)$ early post operative and $2(18.18 \%)$ were late post operative. $5(9.1 \%)$ patients developed hemorrhage, $4(7.27 \%)$ patients developed tubal blockage, surgical emphysema $2(3.63 \%)$ patients and $1(1.8 \%)$ patient developed each for apnea, tracheocutaneous fistula and difficult decannulation.
No mortality occurred in this study due to the tracheostomy procedure.

\section{Discussion}

Tracheostomy is a life saving procedure, the practice of which can be traced since the ancient age. Enjoying the different phases of denial \& acceptance through the history, now it has become an established entity. Not even this, but now-a-days different vistas are being explored to widen the horizons of its utility both in terms of exploring new indications as well as in terms of exploring newer innovative modalities to simplify it $\&$ to reduce its attendant complications. Previously for about 2000 years, it was practiced only to bypass the upper airway obstruction. But now for about half a century it has found its role in the lower airway obstruction to protect the lower airway and to provide ventilatory support by reducing the dead space. Similarly, previously it used to be more an emergency procedure, but now with modern traumatology, it has been assigned still an important role in critically ill patients, being managed electively in ICUs. Hence any condition, whether it be inflammatory, traumatic or neoplastic in origin and which is causing upper airway obstruction, may require tracheostomy to bypass the obstruction. Also as a role to manage the lower airway, bedside tracheostomy in ICU setup has also gained popularity for the patients with prolonged intubation for different indications, to wean them or ease their ventilation by aspirating the bronchial secretions during prolonged ventilatory support with attendant reduction of dead space.

In our study, the highest age incidence of the patients who had tracheostomy was in the 4050 years age group (17 patient-30.9\%) followed by $50-60$ years age group (13 patient-23.63\%) and most of these patients were suffering from carcinoma of larynx $\&$ hypopharynx. In previous study highest frequency of tracheostomy for malignant condition $\&$ the age group was $45-$ 60 years ${ }^{14}$ and $40-70$ years. ${ }^{15}$ Mean age of this study was 40.09 years. In one study in Dhaka Medical Collage Hospital mean age was 46.54 years ${ }^{16}$ and another study in Bangabandhu Sheikh Mujib medical University mean age was $41.66 .^{15}$ 
Here the male was predominant and the male female ratio is 3.2: 1 . This finding is similar with previous study where the ratio was 7.57 : 1, 5.66: 1, \& 3.1: $1 .{ }^{15,17,18}$ Males were more affected due to increased incidence of carcinoma larynx and hypopharynx than female, which is the main indication of tracheostomy.

The current study has observed a wide spectrum of indications for tracheostomy. The commonest indication for tracheostomy in this study was upper airway obstruction due to laryngeal $\&$ hypopharyngeal malignancies. It was observed in $28(50.9 \%)$ patients. This figure is comparable with Ahmed $\mathrm{K}$ et al (1998). ${ }^{14}$ Choudhary et al (2008). ${ }^{15}$ Rahman S H et al $(2001)^{16}$ and Waldron et al (1990) ${ }^{19}$ who had airway obstruction due to tumors in 59\%, $66.66 \%, 63.32 \%$ and $60.5 \%$ of cases in their study. Different studies in world literature show different indications to be the most observed indication in that area, perhaps due to inherent ecological pattern there. Also different age groups have different indications to be the most prevalent due to different reasons. In the current study, 30(54.54\%) patients underwent emergency tracheostomy and 25(45.46\%) underwent tracheostomy electively. Among the 25 elective tracheostomies 15 were done in I.C.U. setting and 10 were done in operation theatre. Among the 15 I.C.U. 9 patients performed tracheostomy for prolonged ventilation due to Guillain Barre Syndrome and 6 patients for prolonged ventilation due to cerebrovascular accidents. The reason for these I.C.U. tracheostomies was to replace the impending prolonged intubation in the patients been managed in I.C.U. Rests of the 10 elective cases were done in operation theatre due to some major head-neck and maxillofacial surgery and also some patient prior to radiotherapy. In the previous study carried out in our country it was found to be emergency tracheostomies 91\% and elective 9\% [16], another study showed that emergency $93 \%$ and $7 \%$ were elective. ${ }^{24}$ Those results were widely varied from our study. But findings of our study was similar with other studies carried out abroad where emergency tracheostomy were found only (16\% to $23 \%)^{20,21}$.
Occurrence of complications is a part of any surgical procedure $\&$ tracheostomy is no exception. However the frequency \& severity of the complications depends on various factors like skill \& experience of the surgeon, patient's anatomical \& physiological factors and the specific approach to the procedure. ${ }^{22}$ In our study complications rate was $25.45 \%$. Previous restrospective studies showed that overall incidence of complications ranged from $5 \%$ to $40 \% .^{23}$ The complication in this study within the range of this study. The rate of complications was similar to

previous studies carried in home \& aborad, ${ }^{14,15,16,18,25}$ where complications rate was $41 \%, 21.66 \%, 39.05 \%, 21.5 \%$ and $27 \%$ respectively. Similarly, emergency situation at the time of the procedure with regards to the deteriorating status of the patient $\&$ the non conducive operative environment also cast its shadow on the outcome. That's why various studies in literature are of the opinion that the frequency of the complications is higher in emergency situations as compared to elective situations and it is 3-5 times more in emergency tracheostomy. ${ }^{24}$ In this study it also 3.66 times more in emergency than elective tracheostomy.

The most frequent complication in our study was haemorrhage which is $9.1 \%$. It is slightly higher than previous studies done in Bangladesh where haemorrhage found in $5.33 \%, 5 \%, 5 \%, 7 \% .{ }^{14,15,16,26}$ But in this study haemorrhage was not serious and treated conservatively. The second commonest complication was tubal blockage which was $4(7.27 \%)$. It is also slight higher than previous studies where the rate was $2 \%, 3.33 \%, 3.5 \%$, $3 \% .{ }^{14,15,16,26}$ Surgical emphysema occurred in $2(3.63 \%)$ cases. But in previous studies surgical emphysema was the commonest complication and much higher than our study which accounts for $21 \%, 6.66 \%, 9.47 \%, 19 \% 14,15,16,26$ This is the presence of air in the subcutaneous tissues evidenced as crepitation under skin on palpation. It usually occurs due to leakage of air between trachea $\&$ tracheostomy tube in the presence of tight suturing of skin \& subcutaneous tissues which acts as ball valve resulting in trapping of the air. $1(1.8 \%)$ patient 
developed each for apnea, tracheocutaneous fistula and difficult decannulation in our study.

There was no mortality attributed to tracheostomy in this present study. No mortality and also no serious complication pointing to the fact that there have been significant improvements not only in the skill of placing a tracheostomy but also in the post operative management of the patients.

\section{Conclusion}

Upper airway obstruction still remains the most common indication for tracheostomy in our centre. Laryngeal carcinoma is the main indication for tracheostomy while infectious conditions which were one of the leading indications a decade ago, have diminished. But prolonged intubation as an indication for tracheostomy is evolving based on recent improvement in the facilities available at our ICU and the use of tracheostomy in the management of neurological patients on prolonged intubation.

\section{References}

1. Pratt LW, Ferlito A, Rinaldo A. Tracheotomy: historical review. Laryngoscope 2008; 118: 1597-1606.

2. Carroll CM, Pahor A. The history of tracheotomy. J Ir Coll Physicians Surg 2001; 30: 237-238.

3. Lloyd D. Dorland's Illustrated Medical Dictionary. Philadephia and London. W.B. Saunders Company, 1986.

4. Pahor AL. Ear, nose and throat in ancient Egypt. $J$ Laryngol Otol 1992; 106: 677-687.

5. Pahor AL. Ear, nose and throat in ancient Egypt. Part III. J Laryngol Otol 1992; 106: 863-873.

6. Oram J \& Bodenham A. In: Intensive care medicine: Annual update 2008. Editor Jean- Louis Vincent. Section viii pp 323. Springer Science+business media inc. New York.

7. Harrel M. Multisystem assessment: Developing an eff ective plan for tracheostomized individual. AARC Times 1999; 23(3):45-47.

8. Jackson C. Tracheostomy. Laryngoscope 1909; 19(4):285-90.

9. Borman $J$ \& Davidson JT. A history of tracheostomy: Si Spiritum Ducit Vivit. Br. J. Anaesth. 1963; 35(6):388-90.

10. Me Clelland RMA, Complications of trachesotomy. British Medical Journal. 1965; 2: 567-9.

11. Goldenberg D, Golz A, Netzer A, Joachims HZ. Tracheotomy: changing indications and a review of 1,130 cases. J Otolaryngol 2002; 31: 211-215.
12. Watkinson JC, Gaze MN, Wilson JA. 'Tracheostomy. In: Stell and Maran's Head and Neck Surgery. Butterworth Heinemann. Oxford, 2000. 163-8.

13. Watkinson JC, Gaze MN, Wilson JA. Treatment options : The principles of surgery. In : Stell and Maran's I lead and Neck Surgery. Butterworth Ileinemann. Oxford, 2000. 49-65.

14. Ahmed K, Rahinan M.A., Rahman S.H, Complications of tracheostomy. Bangladesh Journal of otorhinolaryngology 1998 4)1): 3-6.

15. Choudhary AA, Sultana T, Joardar MAH, Tarafdar $\mathrm{KH}$. A comperative study of elective \& emergency Tracheostomy. Bangladesh J Otolaryngology. 2008;14(2): 57-62.

16. Rahman S.H., Ahmed K, Khan A.F.M, Ahmed S.U, Hanif M.A., Haroon A.A. Islam M.A. study of tracheostomy in Dhaka medical Collage hospital; Bangladesh Journal of Otorhinolaryngolpgy 2001; 7(2): 34-40.

17. Hashemi SB.MD, Gandomi B.MD, Derakhsandeh V. MD. Endoscopic evaluation of the causes of upper airway obstruction leading to tracheostomy, in south of Iran; The Iranian Journal of Otorhinolaryngology Vol.18, No.43 Spring-2006

18. Gilyoma J M, Balumuka D D, Chalya P L. Tenyear experiences with Tracheostomy at a University teaching hospital in Northwestern Tanzania: A retrospective review of 214 cases; Gilyoma et al. World Journal of Emergency Surgery $2011,6: 38$

19. Waldron J, Padgham ND, Hurley SE. Complications of emergency and elective tracheostomy: a retrospective study of 150 consecutive cases. Ann.royal coll.surg. eng. (1990)vol.72: 218-20.

20. Joseph A. Charles L. Trachesotomy: Management, mortality and complications. The American Surgeon 1969; 35(6): 393-6.

21. Mc Clel. Land RMA. Complications of tracheostomy. BMJ1965; 2: 567-9.

22. Durbin CG. Early complications of tracheostomy. Respiratory care April 2005; 50(4):511-15.

23. Goldenberg D, Ari EG, Golz A, Danino J, Netzer A, Joachims H. Tracheotomy complications: a retrospective study of 1130 cases, Otolaryngol Head Neck Surge 2000; 123(4): 495-500.

24. Kato I, Uesugi K, Tracheotomy - the horizontal tracheal incision. J Laryngology and Otology. 2008 vol. $104 ; 322-25$.

25. Manzoor T, Rashid D, Haq AU. Complications of Tracheostomy. Pak armed Forces Med. J. 2000; 50:17.

26. Bhuiyan M A R, Rashid M S, Kamruzzaman M, Islam M S, Ahmed K. Tracheostomy in head-neck malignancy; Bangladesh Journal of Otorhinolaryngol 2010;16(2): 120-125 